\title{
PARTIALLY SINTERED LEAD-FREE CERAMICS FROM PIEZOELECTRIC POWDERS PREPARED VIA CONVENTIONAL FIRING AND SPARK PLASMA SINTERING (SPS) - - CHARACTERIZATION OF MICROSTRUCTURE AND DIELECTRIC PROPERTIES
}

\author{
"KATEŘINA ZLOUŽEOVÁ*, SOŇA HŘÍBALOVÁ*, VOJTĚCH NEČINA*, WILLI PABST*, \\ MARTIN MÍKA*, JAN PETRÁŠEK** \\ *Department of Glass and Ceramics, University of Chemistry and Technology, Prague (UCT Prague), \\ Technická 5, 16628 Prague, Czech Republic \\ **Faculty of Electrical Engineering, Czech Technical University (CTU), \\ Technická 2, 16627 Prague, Czech Republic \\ "E-mail: katerina.zlouzeova@vscht.cz
}

Submitted August 8, 2020; accepted October 7, 2020

\begin{abstract}
Keywords: Lead-free piezoelectrics, Potassium sodium niobate (KNN), Barium titanate (BT), Dielectric constant (relative permittivity), Dielectric function, Electrical properties, Partial sintering, Porosity, Spark plasma sintering (SPS)

This work deals with dielectric properties of lead-free ceramics from piezoelectric powders and focuses on the preparation and characterization of potassium-sodium niobate $\left(\mathrm{K}_{0.5} \mathrm{Na}_{0.5} \mathrm{NbO}_{3}, \mathrm{KNN}\right)$ and barium titanate $\left(\mathrm{BaTiO} \mathrm{O}_{3}, \mathrm{BT}\right)$ ceramics. Ceramic samples with different porosity were prepared from commercial KNN and BT powders by conventional firing in air or spark plasma sintering (SPS) at temperatures $600-1000{ }^{\circ} \mathrm{C}$ for $\mathrm{KNN}$ and $900-1300{ }^{\circ} \mathrm{C}$ for BT, resulting in partially or fully sintered microstructures. Bulk density, apparent density and open porosity were determined using the Archimedes method and closed and total porosities were calculated on the basis of theoretical densities. For both types of ceramics, the porosity decreases with increasing sintering temperature, and for identical temperatures the porosity of SPS samples is lower than for conventional firing, because the pressure applied during SPS promotes densification. For KNN the influence of SPS on the porosity is much larger than for BT. With increasing SPS temperature KNN exhibits a moderate decrease of the alkali content. The results of dielectric property measurements and their frequency dependence via impedance spectroscopy in the range from 10 or $100 \mathrm{~Hz}$ to $1 \mathrm{MHz}$ show that the relative permittivity decreases in all cases with frequency and is usually higher for ceramics prepared via SPS than for conventional firing. This can be explained by the lower porosity and smaller grain size. The absolute values of the relative permittivity at $1 \mathrm{kHz}$ are $134-532$ (conventional firing) and $148-3780$ (SPS) for KNN, and 753 - 1801 (conventional firing) and $923-10380$ (SPS) for BT ceramics.
\end{abstract}

\section{INTRODUCTION}

The piezoelectric effect was first discovered by brothers Pierre and Jacques Curie in 1880 in a quartz single crystal [1-4]. The Curie brothers noticed that when stress was applied to quartz crystals, an electric charge was generated on their surface, an effect that was later called the direct piezoelectric effect $[2,3]$. The opposite effect, in which the crystal creates a stress proportional to the applied electric field is called the converse piezoelectric effect and was predicted by Gabriel Lippmann in 1881 $[1,2]$. The development of piezoelectric materials continued at the beginning of the First World War. At that time, the only available materials, for which the piezoelectric effect was discovered, were the single crystals of quartz and Rochelle salt (sodium potassium tartrate tetrahydrate $\mathrm{KNaC}_{4} \mathrm{H}_{4} \mathrm{O}_{6} \cdot 4 \mathrm{H}_{2} \mathrm{O}$ ). However, their pro-perties were not completely satisfying. Therefore, after World War I, further efforts were made in order to discover alternative piezoelectric materials with better properties. For example, in 1935 Busch and Scherrer discovered the piezoelectric properties of potassium dihydrogen phosphate $\mathrm{KH}_{2} \mathrm{PO}_{4}[2,3]$. During World War II several research groups independently discovered the ferroelectric properties of barium titanate $[2,3,5]$. Subsequently, the piezoelectric effect for barium titanate was verified by Gray in 1946 [2], and thus - due to its ferroelectric properties - barium titanate became the first piezoelectric material that could be produced in polycrystalline (ceramic) form. However, in 1954, Jaffe and his coworkers discovered a ceramic material with much better piezoelectric properties than barium titanate: ceramics based on lead zirconate titanate $\mathrm{Pb}(\mathrm{Zr}, \mathrm{Ti}) \mathrm{O}_{3}$ [6], so-called PZT ceramics. Thanks to its excellent piezoelectric properties, PZT ceramics are still the most widely used piezoelectric material today [1]. It is clear, however, that the toxicity of lead contained in this ceramic is gradually preventing its further use $[4,7,8]$. 
Thus, there is an increasing interest in finding alternative lead-free materials with comparably good piezoelectric properties. Current research interests are mainly focused on lead-free materials based on crystallites with perovskite structure, such as potassium sodium niobate $\mathrm{K}_{x} \mathrm{Na}_{1-x} \mathrm{NbO}_{3}$ (KNN), barium titanate $\mathrm{BaTiO}_{3}$ (BT) and other BT-based ceramics, sodium bismuth titanate $\mathrm{Bi}_{0,5} \mathrm{Na}_{0,5} \mathrm{TiO}_{3}$ (BNT) and bismuth ferrite $\mathrm{BiFeO}_{3}$ (BFO). The recently revived research interest in $\mathrm{BT}$ ceramics is quite remarkable in this context.

Piezoelectric materials are widely used in electrotechnical devices as sensors [9], energy harvesters [10, 11], actuators [4, 12], transducers (e.g. electroacoustic transducers in smartphones, laptops, as speakers and buzzers [4] or as hydrophones - underwater sonars [5, 9, 13-16,]), in high energy applications (e.g. ultrasonic cleaning [4]), medical imaging devices (diagnostic equipment) [17] and in devices for the non-destructive testing of materials $[14,15]$.

Usually, in the preparation of these materials, an effort is made to achieve the highest possible density [18-21], since, for example, the elastic, dielectric and piezoelectric properties decrease with increasing porosity (pore volume fraction) [18-22]. However, in some cases porosity can be an advantage. In particular, the decrease in relative permittivity with increasing porosity increases the values of some figures of merit, which describe the response rate of a piezoelectric transducer $[14,23]$. Porous ceramics can thus show a significant improvement in properties, for example for the application of hydrophones [22, 24], even if, for example, the piezoelectric properties are worse than for their dense counterparts.

This work deals with the preparation of lead-free ceramics from commercially available piezoelectric powders - potassium sodium niobate (KNN) and barium titanate (BT) - by conventional firing and spark plasma sintering (SPS), with the specific intention to prepare these ceramics in partially sintered (i.e. porous) form. The relative permittivity is then measured by impedance spectroscopy in the range from $10 \mathrm{~Hz}$ to $1 \mathrm{MHz}$. The aim of this work is to compare the properties of ceramics samples prepared by conventional firing and SPS.

\section{EXPERIMENTAL}

\section{Raw materials}

The raw materials used for sample preparation were commercially available powders of potassium sodium niobate (CerPoTech, Norway, with particle size $<1 \mu \mathrm{m}$ ), and barium titanate (US Research Nanomaterials, USA, with $99.9 \%$ purity and particle size $200 \mathrm{~nm}$ ). Beside these powders, only polyethylene glycol (PEG 8000, ALDRICH Chemistry) was used as a binder for the preparation of granulates which were subsequently used for uniaxial pressing.

\section{Sample preparation}

Based on typical firing temperatures for both KNN and BT ceramics, a wider range of temperatures was selected with a purpose to prepare partially sintered, i.e. porous, ceramics. The samples were prepared by conventional firing $(\mathrm{KV})$ and by spark plasma sintering (SPS).

\section{Uniaxial pressing and conventional firing}

Both powders of KNN and BT ceramics were mixed with 5 wt. \% PEG and with deionized water, stirred on a laboratory shaker for 24 hours and then dried (in a laboratory oven) at $100{ }^{\circ} \mathrm{C}$ for 24 hours. The granulate was then compressed with a manual hydraulic press into cylindrical tablets with diameter $12.7 \mathrm{~mm}$ using pressures of $94 \mathrm{MPa}$ for $\mathrm{KNN}$ and $110 \mathrm{MPa}$ for BT ceramics.

For samples of KNN ceramics a temperature range of $600-1000{ }^{\circ} \mathrm{C}$ with steps of $50{ }^{\circ} \mathrm{C}$ was chosen, and for samples of BT ceramics a temperature range of $900-1300^{\circ} \mathrm{C}$ with steps of $100^{\circ} \mathrm{C}$ was chosen. The samples were fired for 2 hours in an electrically heated furnace (Nabertherm, Germany) in air with a heating rate of $2{ }^{\circ} \mathrm{C} \cdot \mathrm{min}^{-1}$ and with an uncontrolled cooling rate.

\section{SPS method}

In spark plasma sintering (SPS), a temperature range of $600-1000{ }^{\circ} \mathrm{C}$ with steps of $100{ }^{\circ} \mathrm{C}$ was chosen for KNN ceramics and a temperature range of $900-1300{ }^{\circ} \mathrm{C}$ with steps of $100{ }^{\circ} \mathrm{C}$ for BT ceramics. The samples were sintered under vacuum in a graphite mold with an internal diameter of $20 \mathrm{~mm}$ in a SPS furnace (HP D 10-SD, FCT Systeme, Germany) with a heating rate of $100{ }^{\circ} \mathrm{C} \cdot \mathrm{min}^{-1}$, using an initial pressure of $10 \mathrm{MPa}$, which was raised to $80 \mathrm{MPa}$ after reaching the maximum temperature. The dwell time at maximum temperature was $5 \mathrm{~min}$. The cooling rate was $50{ }^{\circ} \mathrm{C} \cdot \mathrm{min}^{-1}$ to the temperature of $600{ }^{\circ} \mathrm{C}$, then $30{ }^{\circ} \mathrm{C} \cdot \mathrm{min}^{-1}$ to $300{ }^{\circ} \mathrm{C}$ and then uncontrolled.

\section{Characterization}

The bulk density, apparent density and open porosity were determined by the Archimedes method. The relative density $\rho_{r}$, which was subsequently used for calculating the total porosity $\phi$, was directly obtained from knowledge of the theoretical densities $\rho_{0} 4.64 \mathrm{~g} \cdot \mathrm{cm}^{-3}$ for KNN [25] and $6.01 \mathrm{~g} \cdot \mathrm{cm}^{-3}$ for BT [26]. The chemical composition was determined by X-ray fluorescence analysis (XRF) on the XRF spectrometer ARL 9400 XP (Thermo ARL, Switzerland) to determine whether KNN was depleted of alkaline elements $\mathrm{K}$ and $\mathrm{Na}$ during sintering. The analysis was performed for KNN ceramics samples prepared by the SPS method. The dielectric properties of the samples thus prepared and characterized were subsequently measured via impedance spectroscopy. The measurement was performed at various 
Table 1. List of workplaces, instruments and parameters for dielectric measurements of samples; (1) - UCT Prague, Department of Inorganic Technology, (2) - CTU, Faculty of Electrical Engineering, (3) - UCT Prague, Department of Glass and Ceramics.

(1)

\begin{tabular}{lcccc}
\hline Instrument & $\begin{array}{c}\text { Solartron Frequency Response } \\
\text { Analyser SI 1250 }\end{array}$ & FLUKE PM6306 & $\begin{array}{c}\text { Autolab } \\
\text { PGSTAT 30 }\end{array}$ & $\begin{array}{c}\text { MOTECH MT 4090 } \\
\text { LCR Meter }\end{array}$ \\
\hline Arrangement & Three-point & Two-point & Two-point & Two-point \\
\hline Frequency range (Hz) & $65000-0.01$ & $1000000-50$ & $1000000-1$ & $200000-100$ \\
\hline Voltage amplitude (V) & 0.02 & 1 & 0.5 & $0.25 / 1$ \\
\hline
\end{tabular}

workplaces and on various instruments, the list of which, together with the measurement parameters, is summarized in Table 1. All dielectric measurements were performed at room temperature.

The following relations (from [27]) were used to calculate the real and imaginary part of the relative permittivity from the primary data (real and imaginary part of the impedance) measured by impedance spectroscopy:

$$
\begin{aligned}
& \varepsilon^{\prime}=\frac{t}{\omega A \varepsilon_{0}} \frac{Z}{Z^{\prime 2}+Z^{\prime \prime 2}} \\
& \varepsilon_{r}^{\prime \prime}=\frac{t}{\omega A \varepsilon_{0}} \frac{Z^{\prime}}{Z^{\prime 2}+Z^{\prime \prime 2}}
\end{aligned}
$$

where $A$ is the cross-sectional area of the sample, $t$ the thickness of the sample, $\varepsilon_{0}$ the vacuum permittivity, $Z^{\prime}$ the real part of the impedance, $Z^{\prime \prime}$ the imaginary part of the impedance, $\varepsilon_{r}^{\prime}$ the real part of the relative permittivity and $\varepsilon_{r}^{\prime \prime}$ the imaginary part of the relative permittivity.

The following relationship [27] was then used to calculate the loss tangent $\tan \delta$ :

$$
\tan \delta=\frac{\varepsilon_{r}^{\prime \prime}}{\varepsilon_{r}^{\prime}}
$$

\section{RESULTS}

Bulk density, apparent density and porosity

\section{KNN ceramics}

Basic microstructural parameters (bulk density $\rho$, apparent density $\rho_{A}$, open porosity $\phi_{\text {open }}$, closed porosity $\phi_{\text {closed }}$ and total porosity $\phi$ ) are given in Tables 2 and 3 for the samples of KNN ceramics prepared by SPS and KV, respectively.

For KNN ceramics prepared by SPS, there is evidently an increase in the bulk density $\rho$ and a decrease in the open porosity $\phi_{\text {open }}$ and the total porosity $\phi$ with increasing sintering temperature. On the other hand, the apparent density, being in the range of $4.37-4.46 \mathrm{~g} \cdot \mathrm{cm}^{-3}$, does not differ very much for the different sintering temperatures, which indicates that the proportion of closed porosity remains approximately constant as soon as a certain minimum sintering temperature is exceeded.
For KNN ceramics prepared by conventional firing $(\mathrm{KV})$ an increase in bulk density and a decrease in apparent and total porosity can also be observed with increasing firing temperature, but the trend is less pronounced, and the absolute values are at a lower level. The apparent density is in the range of $4.31-4.43 \mathrm{~g} \cdot \mathrm{cm}^{-3}$, so its value increases slightly with the firing temperature, but also in this case the proportion of closed porosity remains approximately constant.

Table 2. Basic microstructural parameters for samples of KNN ceramics prepared by SPS.

\begin{tabular}{cccccc}
\hline $\begin{array}{c}T \\
\left({ }^{\circ} \mathrm{C}\right)\end{array}$ & $\begin{array}{c}\rho \\
\left(\mathrm{g} \cdot \mathrm{cm}^{-3}\right)\end{array}$ & $\begin{array}{c}\rho_{A} \\
\left(\mathrm{~g} \cdot \mathrm{cm}^{-3}\right)\end{array}$ & $\begin{array}{c}\phi_{\text {open }} \\
(1)\end{array}$ & $\begin{array}{c}\phi_{\text {closed }} \\
(1)\end{array}$ & $\begin{array}{c}\phi \\
(1)\end{array}$ \\
\hline 600 & 2.57 & 4.37 & 0.412 & 0.034 & 0.446 \\
700 & 3.15 & 4.40 & 0.285 & 0.037 & 0.322 \\
800 & 4.01 & 4.46 & 0.099 & 0.036 & 0.135 \\
900 & 4.41 & 4.43 & 0.005 & 0.045 & 0.050 \\
1000 & 4.44 & 4.46 & 0.006 & 0.038 & 0.044 \\
\hline
\end{tabular}

Table 3. Basic microstructural parameters for samples of KNN ceramics prepared by $\mathrm{KV}$.

\begin{tabular}{cccccc}
\hline $\begin{array}{c}T \\
\left({ }^{\circ} \mathrm{C}\right)\end{array}$ & $\begin{array}{c}\rho \\
\left(\mathrm{g} \cdot \mathrm{cm}^{-3}\right)\end{array}$ & $\begin{array}{c}\rho_{A} \\
\left(\mathrm{~g} \cdot \mathrm{cm}^{-3}\right)\end{array}$ & $\begin{array}{c}\phi_{\text {open }} \\
(1)\end{array}$ & $\begin{array}{c}\phi_{\text {closed }} \\
(1)\end{array}$ & $\begin{array}{c}\phi \\
(1)\end{array}$ \\
\hline 650 & 2.42 & 4.31 & 0.438 & 0.040 & 0.478 \\
700 & 2.43 & 4.32 & 0.438 & 0.039 & 0.477 \\
750 & 2.46 & 4.35 & 0.434 & 0.035 & 0.469 \\
800 & 2.28 & 4.38 & 0.479 & 0.029 & 0.508 \\
850 & 2.55 & 4.39 & 0.420 & 0.031 & 0.451 \\
900 & 2.45 & 4.39 & 0.443 & 0.030 & 0.473 \\
950 & 2.69 & 4.42 & 0.390 & 0.029 & 0.419 \\
1000 & 2.98 & 4.43 & 0.327 & 0.030 & 0.358 \\
\hline
\end{tabular}

It is evident that for comparable firing or sintering temperatures the total porosities of samples prepared by SPS are much lower than for samples prepared by $\mathrm{KV}$ (e.g. samples fired at temperatures of 700, 800, 900 and $1000{ }^{\circ} \mathrm{C}$ have porosities 32, 14, 5 and $4 \%$ for SPS and 48, 51, 47 and $36 \%$ for KV). This is of course due to the pressure applied in SPS. The applied pressure is responsible for the much greater (and faster) densification at a given temperature. 


\section{BT ceramics}

Basic microstructural parameters (bulk density $\rho$, appa-rent density $\rho_{A}$, open porosity $\phi_{\text {open }}$, closed porosity $\phi_{\text {closed }}$ and total porosity $\phi$ ) are given in Tables 4 and 5 for the samples of BT ceramics prepared by SPS and by KV, respectively.

As with KNN ceramics, for BT ceramics prepared by either SPS or KV an increase in bulk density $\rho$ can be observed with increasing sintering temperature, indicating higher densification and decreasing total porosity $\phi$ and open porosity $\phi_{\text {open }}$ with increasing sintering temperature. Again, the apparent density $\rho_{A}$ and thus also the proportion of closed porosity is approximately constant for all samples, irrespective of the sintering temperature.

Table 4. Basic microstructural parameters for samples of BT ceramics prepared by SPS.

\begin{tabular}{cccccc}
\hline $\begin{array}{c}T \\
\left({ }^{\circ} \mathrm{C}\right)\end{array}$ & $\begin{array}{c}\rho \\
\left(\mathrm{g} \cdot \mathrm{cm}^{-3}\right)\end{array}$ & $\begin{array}{c}\rho_{A} \\
\left(\mathrm{~g} \cdot \mathrm{cm}^{-3}\right)\end{array}$ & $\begin{array}{c}\phi_{\text {open }} \\
(1)\end{array}$ & $\begin{array}{c}\phi_{\text {closed }} \\
(1)\end{array}$ & $\begin{array}{c}\phi \\
(1)\end{array}$ \\
\hline 900 & 3.61 & 5.92 & 0.390 & 0.009 & 0.399 \\
1000 & 4.58 & 5.95 & 0.230 & 0.008 & 0.238 \\
1100 & 5.47 & 5.77 & 0.051 & 0.039 & 0.090 \\
1200 & 5.93 & 5.98 & 0.009 & 0.005 & 0.014 \\
1300 & 5.97 & 5.99 & 0.003 & 0.004 & 0.007 \\
\hline
\end{tabular}

Table 5. Basic microstructural parameters for samples of BT ceramics prepared by KV.

\begin{tabular}{cccccc}
\hline $\begin{array}{c}T \\
\left({ }^{\circ} \mathrm{C}\right)\end{array}$ & $\begin{array}{c}\rho \\
\left(\mathrm{g} \cdot \mathrm{cm}^{-3}\right)\end{array}$ & $\begin{array}{c}\rho_{A} \\
\left(\mathrm{~g} \cdot \mathrm{cm}^{-3}\right)\end{array}$ & $\begin{array}{c}\phi_{\text {open }} \\
(1)\end{array}$ & $\begin{array}{c}\phi_{\text {closed }} \\
(1)\end{array}$ & $\begin{array}{c}\phi \\
(1)\end{array}$ \\
\hline 900 & 3.51 & 5.92 & 0.406 & 0.009 & 0.415 \\
1000 & 3.76 & 5.95 & 0.369 & 0.006 & 0.375 \\
1100 & 4.38 & 5.97 & 0.266 & 0.005 & 0.271 \\
1200 & 5.42 & 5.65 & 0.041 & 0.058 & 0.099 \\
1300 & 5.90 & 5.94 & 0.007 & 0.011 & 0.019 \\
\hline
\end{tabular}

\section{$\mathrm{X}$-ray fluorescence analysis}

$\mathrm{X}$-ray fluorescence (XRF) analysis was performed for the KNN ceramic samples prepared by SPS, in order to determine the elemental composition after sintering to different temperatures. For the purpose of comparison XRF analysis was also performed for the original

Table 6. Composition of oxides in the original KNN powder ("Raw") and in samples of KNN ceramics prepared by SPS at different temperatures.

\begin{tabular}{cccc}
\hline $\begin{array}{c}T \\
\left({ }^{\circ} \mathrm{C}\right)\end{array}$ & $\begin{array}{c}\mathrm{Na}_{2} \mathrm{O} \\
(\text { wt. \%) }\end{array}$ & $\begin{array}{c}\mathrm{K}_{2} \mathrm{O} \\
\text { (wt. \%) }\end{array}$ & $\begin{array}{c}\mathrm{Nb}_{2} \mathrm{O}_{5} \\
(\text { wt. \%) }\end{array}$ \\
\hline Raw & 10.68 & 13.33 & 75.99 \\
600 & 9.62 & 13.13 & 77.25 \\
700 & 9.34 & 12.74 & 77.92 \\
800 & 9.01 & 12.84 & 78.15 \\
900 & 9.47 & 13.06 & 77.48 \\
1000 & 9.58 & 12.81 & 77.61 \\
\hline
\end{tabular}

as-supplied KNN powder (designated as "Raw”). Table 6 lists the mass contents of sodium, potassium and niobium oxides for the different sintering temperatures and for the original KNN powder.

The detected mass fractions of alkali metal oxides in the KNN ceramics and their comparison with the original KNN powder indicate that during the SPS process there is a slight decrease in $\mathrm{Na}_{2} \mathrm{O}$ content (from the original 10.7 wt. \% to values in the range of 9.0 - 9.6 wt. \%), but the difference between the individual sintering temperatures seems to be negligible (e.g. the value of $9.6 \mathrm{wt}$. \% correspond to both the lowest firing temperature of $600{ }^{\circ} \mathrm{C}$ and the highest $1000{ }^{\circ} \mathrm{C}$ ).

Also in the case of $\mathrm{K}_{2} \mathrm{O}$, a slight decrease can be observed (from the original 13.3 wt. \% to values in the range of 12.7 - 13.1 wt. \%), but compared to $\mathrm{Na}_{2} \mathrm{O}$ this decrease seems to be almost negligible, probably because the potassium is considerably larger and thus less mobile than the sodium ion. Although information about the volatility of $\mathrm{Na}_{2} \mathrm{O}$ and $\mathrm{K}_{2} \mathrm{O}$ often appears in the literature and is mentioned as a problem in the preparation of KNN ceramics [28], in our case the XRF analysis revealed that alkalis volatilize only in very small amounts during the SPS process. With respect to the fact that SPS works in vacuum, this might seem surprising, but on the other hand one has to take into account the fact that also the processing times are relatively short in SPS, which might be a major factor preventing volatilization (which is of course kinetically governed by the diffusion rates).

\section{Impedance spectroscopy}

For selected samples impedance spectroscopy measurements have been performed on four different instruments. However, systematic characterization of all samples has been performed only on two instruments, MOTECH and Autolab. While the first of these provides data only for a few selected frequencies, the latter yields the complete frequency dependence of the complex dielectric function. Therefore, all graphs shown in this section are based on data from the Autolab instrument. Results of all other measurements are summarized in Tables 7-10.

From the measured data, the values for the real parts of the relative permittivity $\varepsilon_{r}^{\prime}$, the imaginary parts of the relative permittivity $\varepsilon_{r}^{\prime \prime}$ and the tangent loss tan $\delta$ (all depending on the frequency) were calculated using Equations 1-3.

\section{KNN ceramics}

The dependence of the real part of the relative permittivity $\varepsilon_{r}^{\prime}$ on the frequency for the Autolab instrument is shown in Figure 1. It can be seen that samples of KNN ceramics prepared by SPS usually have higher values compared to samples prepared by conventional firing, which is in line with the literature: due to faster heating rate and shorter dwell time of the samples at maximum 
temperature during the SPS process, excessive grain growth is suppressed. It is known that the dielectric properties are dependent on the grain size (the smaller the grains, the higher the relative permittivity due to the high resistivity of the grain boundary [19-22]). This was confirmed for most samples, with the exception of the SPS 1000 sample, where it shows very low $\varepsilon_{r}^{\prime}$ values, but this was probably an artefact caused by degradation of the silver electrode during the measurements.

Overall, it can be stated that in the samples of KNN ceramics the real parts of the relative permittivity $\varepsilon_{r}^{\prime}$ show clearly decreasing trends with increasing frequency. Absolute values (only for Solartron, FLUKE and Autolab, as the MOTECH results deviated from trends) range between 6580 - 32900 for SPS and 411 - 2144 for KV at a frequency of $10 \mathrm{~Hz}$ and between $60-132$ for SPS and 53 - 104 for KV at a frequency of $1 \mathrm{MHz}$.

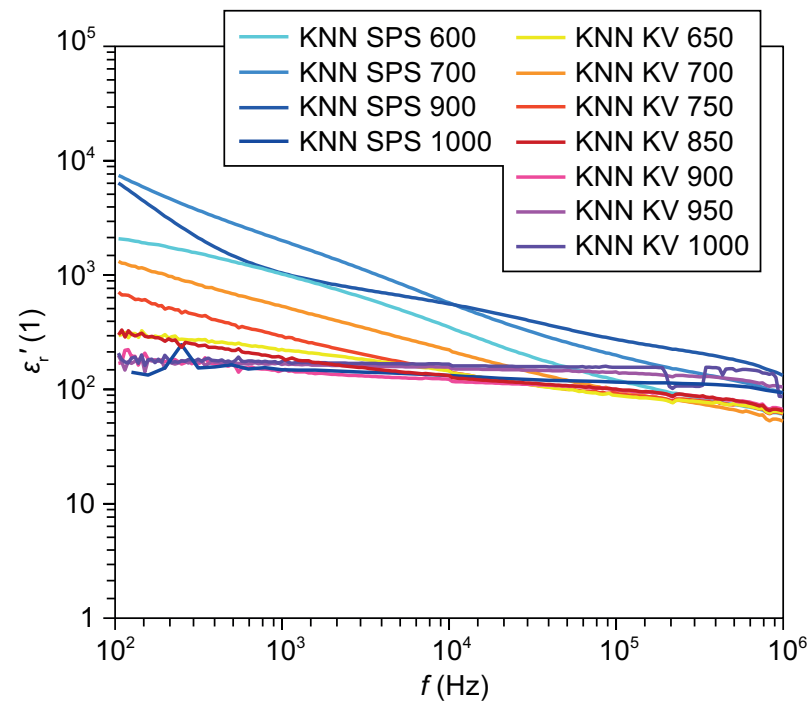

Figure 1. Dependence of $\varepsilon_{r}^{\prime}$ on frequency for samples of KNN ceramics (Autolab).

The dependence of the imaginary part of the relative permittivity $\varepsilon_{r}^{\prime \prime}$ on the frequency for the Autolab instrument is shown in Figure 2. The values of $\varepsilon_{r}^{\prime \prime}$ are usually higher for the samples prepared by SPS (except for the sample SPS 1000, probably for the reason mentioned above in the context of $\varepsilon_{r}^{\prime}$ ).

The frequency dependence of the loss tangent $\tan \delta$ is shown in Figure 3. Actually, for this quantity the measurements provide results without any significant frequency dependence. The values of loss tangent are in the range of $0.03-0.96$ for samples prepared by $\mathrm{KV}$ and slightly larger $(0.09-1.56)$ for samples prepared by SPS.

The values $\varepsilon_{r}^{\prime}, \varepsilon_{r}^{\prime \prime}$ and $\tan \delta$ for frequencies 1,10 , $100 \mathrm{kHz}$ are summarized in the tables, for samples of KNN ceramics prepared by SPS in Table 7 and for samples of KNN ceramics prepared by KV in Table 8. It can be seen that the values of $\varepsilon_{r}^{\prime}, \varepsilon_{r}^{\prime \prime}$ and $\tan \delta$ are higher for samples prepared by SPS.

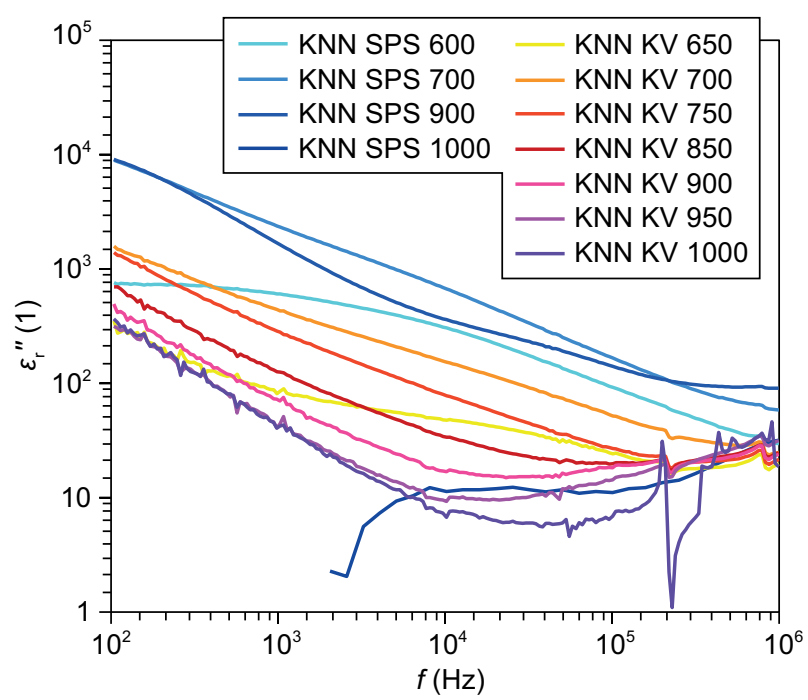

Figure 2. Dependence of $\varepsilon_{r}^{\prime \prime}$ on frequency for samples of KNN ceramics (Autolab).

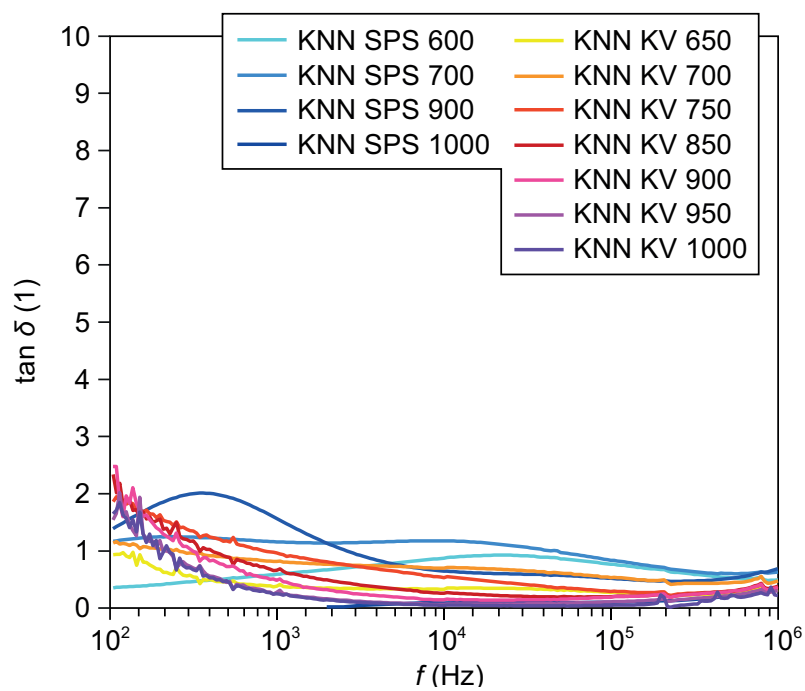

Figure 3. Dependence of $\tan \delta$ on frequency for samples of KNN ceramics (Autolab).

Table 7. Range of values of $\varepsilon_{r}^{\prime}, \varepsilon_{r}^{\prime \prime}$ and $\tan \delta$ for different frequencies measured on different instruments for samples of KNN ceramics prepared by SPS.

\begin{tabular}{lcccc}
\hline Apparatus & $\begin{array}{c}f \\
(\mathrm{kHz})\end{array}$ & $\begin{array}{c}\varepsilon_{r}^{\prime} \\
(1)\end{array}$ & $\begin{array}{c}\varepsilon_{r}^{\prime \prime} \\
(1)\end{array}$ & $\begin{array}{c}\tan \delta \\
(1)\end{array}$ \\
\hline Solartron & & $1090-3780$ & $767-4110$ & $0.70-2.98$ \\
FLUKE & 1 & $832-2263$ & $355-2716$ & $0.32-1.20$ \\
Autolab & 1 & $148-2004$ & $603-2320$ & $0.59-1.56$ \\
MOTECH & & $3-1178$ & $15-2827$ & $0.07-23.24$ \\
\hline Solartron & & $521-1210$ & $221-1060$ & $0.31-1.20$ \\
FLUKE & \multirow{4}{*}{10} & $126-795$ & $153-552$ & $0.74-1.31$ \\
Autolab & & $132-571$ & $11-669$ & $0.09-1.17$ \\
MOTECH & & $30-678$ & $2-856$ & $0.08-5.22$ \\
\hline Solartron & & - & - & - \\
FLUKE & \multirow{4}{*}{100} & $115-691$ & $37-142$ & $0.11-0.61$ \\
Autolab & & $5-293$ & $11-141$ & $0.10-0.84$ \\
MOTECH & & & $11-244$ & $0.12-5.33$ \\
\hline
\end{tabular}


Table 8. Range of values of $\varepsilon_{r}^{\prime}, \varepsilon_{r}^{\prime \prime}$ and $\tan \delta$ for different frequencies measured on different instruments for samples of $\mathrm{KNN}$ ceramics prepared by KV.

\begin{tabular}{|c|c|c|c|c|}
\hline Apparatus & $\begin{array}{c}f \\
(\mathrm{kHz})\end{array}$ & $\begin{array}{l}\varepsilon_{r}^{\prime} \\
(1)\end{array}$ & $\begin{array}{l}\varepsilon_{r}^{\prime \prime} \\
(1)\end{array}$ & $\begin{array}{c}\tan \delta \\
(1)\end{array}$ \\
\hline Solartron & \multirow{4}{*}{1} & $233-507$ & $38-797$ & $0.16-1.57$ \\
\hline FLUKE & & $134-219$ & $17-111$ & $0.13-0.60$ \\
\hline Autolab & & $146-532$ & $42-432$ & $0.24-0.96$ \\
\hline MOTECH & & $14-624$ & $9-503$ & $0.24-3.79$ \\
\hline Solartron & \multirow{4}{*}{10} & $152-256$ & $21-182$ & $0.40-0.71$ \\
\hline FLUKE & & $104-123$ & 4-64 & $0.03-0.60$ \\
\hline Autolab & & $122-221$ & $7-154$ & $0.04-0.69$ \\
\hline MOTECH & & 14-159 & $12-278$ & $0.08-9.83$ \\
\hline Solartron & \multirow{4}{*}{100} & - & - & - \\
\hline FLUKE & & $69-119$ & $3-33$ & $0.2-0.48$ \\
\hline Autolab & & $89-156$ & $7-52$ & $0.04-0.53$ \\
\hline MOTECH & & $20-123$ & $70-117$ & $0.74-5.76$ \\
\hline
\end{tabular}

\section{BT ceramics}

The dependence of the real part of the relative permittivity $\varepsilon_{r}^{\prime}$, on the frequency for the Autolab instrument is shown in Figure 4. It can be seen that all KV samples, and in addition the SPS 900 and 1000 samples, show a similar course of frequency dependence with a slightly decreasing trend (and with an indication of increasing permittivity values with increasing sintering temperature, i.e. with decreasing porosity), while the SPS 1100, 1200 and 1300 show a qualitatively significantly different course (with a strong frequency dependence), which must be related to a relatively low porosity $(0.7-9.0 \%)$ in combination with a relatively small grain size. Absolute values obtained with the Autolab instrument decrease from $1104-27277$ for SPS and 766 - 1541 for KV at a frequency of $100 \mathrm{~Hz}$ to $57-229$ for SPS and $392-848$ for KV at a frequency of $1 \mathrm{MHz}$, see Tables 9-10.

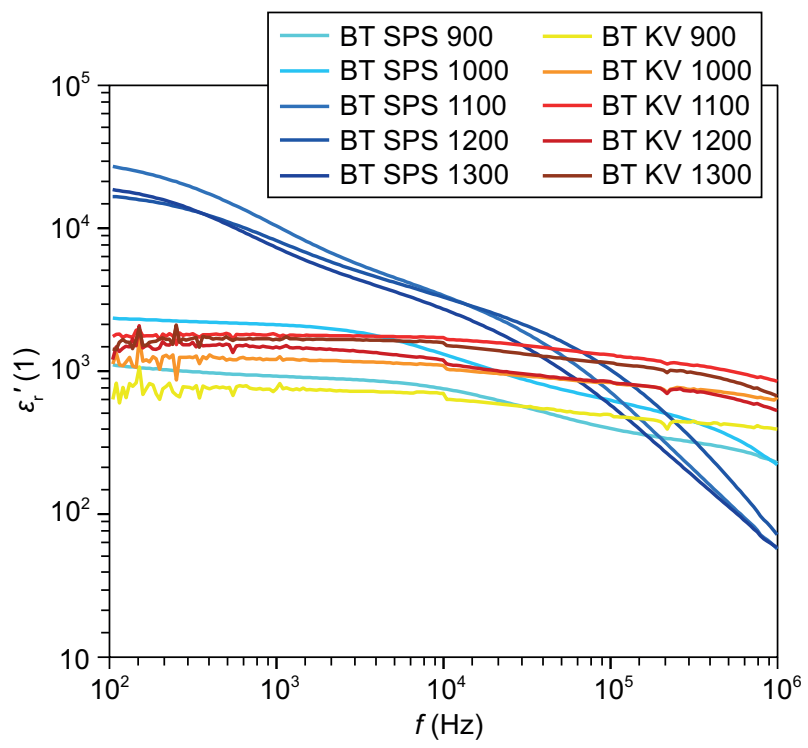

Figure 4. Dependence of $\varepsilon_{r}^{\prime}$ on frequency for samples of BT ceramics (Autolab).
The dependence of the imaginary part of the relative permittivity $\varepsilon_{r}^{\prime \prime}$ on the frequency for the Autolab instrument is shown in Figure 5. From the frequency dependences of the imaginary part of the relative permittivity it can be concluded that the values corresponding to the samples obtained by SPS at a sufficiently high temperature $\left(1100-1300{ }^{\circ} \mathrm{C}\right)$ are orders of magnitude higher than those of the samples prepared by KV.

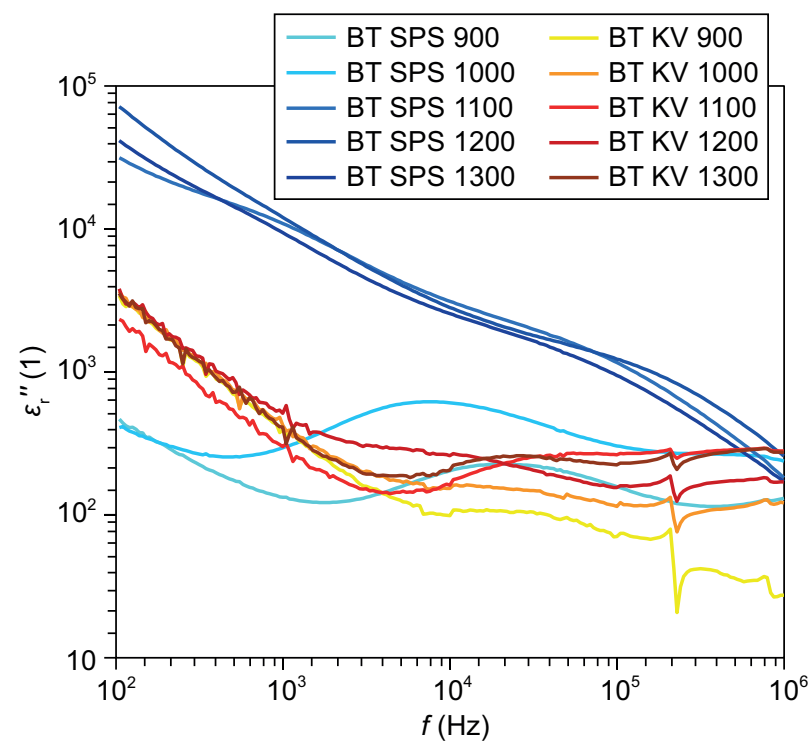

Figure 5. Dependence of $\varepsilon_{r}^{\prime \prime}$ on frequency for samples of BT ceramics (Autolab).

The dependence of the loss tangent $\tan \delta$ on the frequency for the Autolab instrument is shown in Figure 6. The values of loss tangent for samples of BT ceramics (measured with the Autolab instrument) range approximately between 0.0 - 5.0 (i.e. significantly larger than for KNN ceramics) and it seems that the course of the curve is similar for all samples.

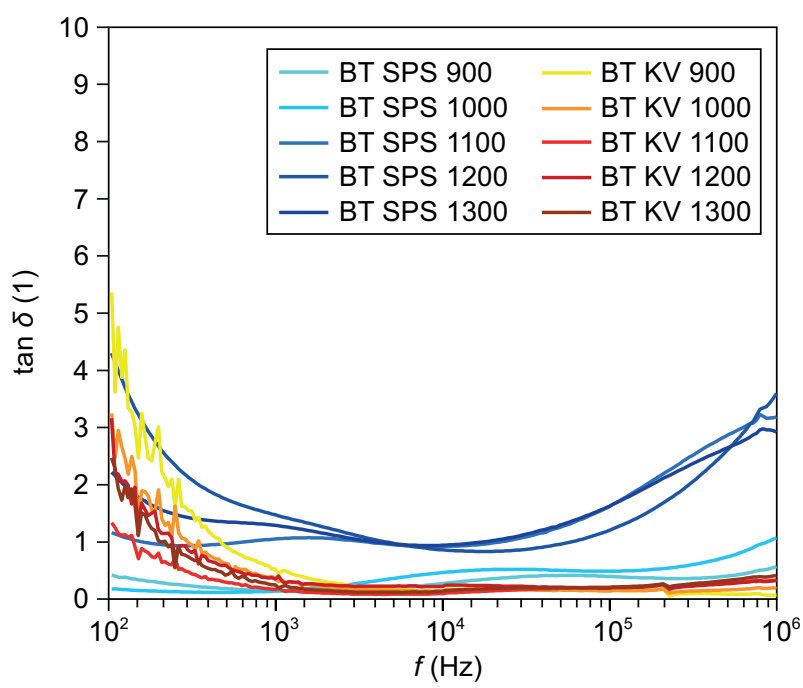

Figure 6. Dependence of $\tan \delta$ on frequency for samples of BT ceramics (Autolab). 
The values $\varepsilon_{r}^{\prime}, \varepsilon_{r}^{\prime \prime}$ and $\tan \delta$ for frequencies 1,10 , $100 \mathrm{kHz}$ are summarized in the tables, for samples of BT ceramics prepared by SPS in Table 9 and for samples of BT ceramics prepared by KV in Table 10. In comparison with the KNN ceramics prepared in this work, these values are significantly higher for the BT ceramics. For the sample prepared by SPS at a temperature of $1300{ }^{\circ} \mathrm{C}$, a surprisingly high value of $\varepsilon_{n}^{\prime}$, was achieved at a frequency of $1000 \mathrm{~Hz}-10380$.

Table 9. Range of values of $\varepsilon_{r}^{\prime}, \varepsilon_{r}^{\prime \prime}$ and $\tan \delta$ for different frequencies measured on different instruments for samples of BT ceramics prepared by SPS.

\begin{tabular}{lcccl}
\hline Apparatus & $\begin{array}{c}f \\
(\mathrm{kHz})\end{array}$ & $\begin{array}{c}\varepsilon_{r}^{\prime} \\
(1)\end{array}$ & $\begin{array}{c}\varepsilon_{r}^{\prime \prime} \\
(1)\end{array}$ & \multicolumn{1}{c}{$\begin{array}{c}\tan \delta \\
(1)\end{array}$} \\
\hline Autolab & \multirow{2}{*}{1} & $923-10380$ & $132-12005$ & $0.14-1.47$ \\
MOTECH & & $127-23285$ & $694-21619$ & $0.39-129.82$ \\
\hline Autolab & \multirow{2}{*}{10} & $755-3385$ & $203-3107$ & $0.27-0.94$ \\
MOTECH & & $22-6718$ & $764-5875$ & $0.87-35.42$ \\
\hline Autolab & \multirow{2}{*}{100} & $398-1024$ & $157-1225$ & $0.39-1.62$ \\
MOTECH & & $41-1441$ & $385-1916$ & $1.02-17.66$ \\
\hline
\end{tabular}

Table 10. Range of values of $\varepsilon_{r}^{\prime}, \varepsilon_{r}^{\prime \prime}$ and $\tan \delta$ for different frequencies measured on different instruments for samples of BT ceramics prepared by KV.

\begin{tabular}{lcccr}
\hline Apparatus & $\begin{array}{c}f \\
(\mathrm{kHz})\end{array}$ & $\begin{array}{c}\varepsilon_{r}^{\prime} \\
(1)\end{array}$ & $\begin{array}{c}\varepsilon_{r}^{\prime \prime} \\
(1)\end{array}$ & \multicolumn{1}{c}{$\begin{array}{c}\tan \delta \\
(1)\end{array}$} \\
\hline Autolab & \multirow{2}{*}{1} & $753-1801$ & $300-511$ & $0.17-0.52$ \\
MOTECH & & $466-4918$ & $66-14110$ & $0.1-3.29$ \\
\hline Autolab & \multirow{2}{*}{10} & $700-1716$ & $98-258$ & $0.09-0.22$ \\
MOTECH & & $159-9135$ & $584-6691$ & $0.56-3.81$ \\
\hline Autolab & \multirow{2}{*}{100} & $498-1298$ & $70-263$ & $0.14-0.20$ \\
MOTECH & & $227-1259$ & $151-791$ & $0.12-3.48$ \\
\hline
\end{tabular}

\section{CONCLUSION}

This work dealt with the dielectric properties of lead-free ceramics from piezoelectric powders, namely the preparation and characterization of potassium sodium niobate $\left(\mathrm{K}_{0.5} \mathrm{Na}_{0.5} \mathrm{NbO}_{3}\right.$, KNN) and barium titanate $\left(\mathrm{BaTiO}_{3}, \mathrm{BT}\right)$ ceramics. In the experimental part of this work, ceramics samples were prepared from commercial $\mathrm{KNN}$ and BT powders by conventional firing and spark plasma sintering (SPS) with a wide range of temperatures in order to prepare partially sintered (porous) ceramics. It should be emphasized that the ceramic samples prepared and characterized in this work are not piezoelectric, because the process of "poling" was not applied.

Bulk density, apparent density, open porosity, closed porosity and total porosity of the prepared samples were determined by the Archimedes method. It is clear that for both KNN and BT the bulk density increases (and the open and total porosity decreases) with increasing sintering temperature (while the apparent density remains approximately constant, indicating a relatively constant volume fraction of closed porosity). For the samples of KNN ceramics it was observed that for the same sintering temperatures, the total porosity of the samples prepared by SPS is always significantly lower than for samples prepared by conventional firing, because the pressure applied during the SPS process promotes densification. Compared to BT, the effect of the use of SPS on the porosity of the prepared samples is significantly greater for KNN. This is probably related to the fact that in the case of $\mathrm{KNN}$ the application of pressure has a significantly greater effect on compaction than in the case of BT, which may be due to a different sintering mechanism.

The chemical composition of KNN samples prepared by SPS and the original KNN powder was determined by X-ray fluorescence analysis. This analysis was performed only for $\mathrm{KNN}$, because in literature there is often a reference to the volatility of alkali oxides during firing. But as the SPS temperature increases, only a very slight decrease in the alkali content could be observed, so that alkali volatilization does not appear to be a significant complication in the preparation of KNN ceramics by SPS.

Measurements of dielectric properties and their frequency dependence by impedance spectroscopy were performed on four different instruments (at three different workplaces). For the samples of KNN ceramics it was found that the real and imaginary parts of relative permittivity show a decreasing trend and the results show that the absolute values of relative permittivity are higher for samples prepared by SPS (compared to samples prepared by conventional firing), which is caused by the higher densification in the SPS process and thus the lower porosity of the samples. The loss tangent for the samples of KNN ceramics do not have a clear trend with frequency for all samples, but the values are generally higher for the samples prepared by SPS. The frequency dependence of the real part of the relative permittivity for the samples of BT ceramics is also decreasing. The real part of the relative permittivity for samples SPS 1100, 1200 and 1300 shows (in contrast to samples prepared by conventional firing and samples SPS 900 and 1000) a strong frequency dependence, which may be due to relatively low porosity and small grain size. The frequency dependence of the imaginary part of the relative permittivity of BT prepared by SPS at a sufficiently high temperature $\left(1100-1300{ }^{\circ} \mathrm{C}\right)$ attains values that are higher by orders of magnitude compared to samples by SPS at a lower temperature and compared to samples prepared by conventional firing. The frequency dependence of the loss tangent shows a very similar course for all BT samples. Similar to KNN, also for BT ceramics the loss tangent values are higher for samples prepared by SPS. 
Acknowledgement

This work is part of the project "Partially and fully sintered ceramics - preparation, microstructure, properties, modelling and theory of sintering" (GA18-17899S) supported by Czech Science Foundation (Grantová agentura České republiky/GAČR). The authors would like to thank Ing. Simona Randáková (Central Laboratories, UCT Prague) for the X-ray fluorescence analyses and especially Ing. Michaela Plevová, Ing. Jaromir Hnát, Ph.D., doc. Ing. Martin Paidar, Ph.D. (Department of Inorganic Technology, UCT Prague) for making the first test measurements for this work on the Solartron instrument.

\section{REFERENCES}

1. Jaffe B., Cook W.R., Jaffe H. (1971). Piezoelectric Ceramics. Academic Press Inc.

2. Uchino K. (2010). Advanced Piezoelectric Materials. Science and Technology. $1^{\text {st }}$ ed. Woodhead.

3. von Hippel A. (1994). Dielectrics and Waves. $2^{\text {nd }}$ ed. Artech House.

4. Zheng T., Wu, J., Xiao D., Zhu J. (2018): Recent development in lead-free perovskite piezoelectric bulk materials. Progress in Materials Science, 98, 552-624. doi: 10.1016/j. pmatsci.2018.06.002

5. Tichý J., Erhart J., Kittinger E., Př́ivratská J. (2010). Fundamentals of Piezoelectric Sensorics: Mechanical, Dielectric, and Thermodynamical Properties of Piezoelectric Materials. Springer.

6. Jaffe B., Roth, R.S., Marzullo S. (1954): Piezoelectric properties of lead zirconate-lead titanate solid-solution ceramics. Journal of Applied Physics, 25, 809-810. doi: 10. $1063 / 1.1721741$

7. Ibn-Mohammed T., Koh S.C.L., Reaney I.M., Acquaye A., Wang D., Taylor S., Genovese A. (2016): Integrated hybrid life cycle assessment and supply chain environmental profile evaluations of lead-based (lead zirconate titanate) versus lead-free (potassium sodium niobate) piezoelectric ceramics. Energy \& Environmental Science, 9, 3495-3520. doi: $10.1039 / \mathrm{c} 6 \mathrm{ee} 02429 \mathrm{~g}$

8. Song H.C., Cho K.H., Park H.Y., Ahn C.W., Nahm S., Uchino K., Park S.H., Lee H.G. (2007): Microstructure and piezoelectric properties of $(1-x)\left(\mathrm{Na}_{0.5} \mathrm{~K}_{0.5}\right) \mathrm{NbO}_{3-x} \mathrm{LiNbO}_{3}$ ceramics. Journal of the American Ceramic Society, 90, 1812-1816. doi: 10.1111/j.1551-2916.2007.01698.x

9. Nesterov A.A., Topolov V.Y., Tolstunov M.I., Isaeva A.N (2019): Improved piezoelectric performance and hydrostatic parameters of a novel 2-0-2-0 composite. Materials Letters, 252, 158-160. doi: 10.1016/j.matlet.2019.05.104

10. Coondoo I., Panwar N., Kholkin A. (2013): Lead-free piezoelectrics: Current status and perspectives. Journal of Advanced Dielectrics, 03, 1330002-1-1330002-22. doi: 10. $1142 / \mathrm{s} 2010135 \times 13300028$

11. Roscow J.I., Pearce H., Khanbareh H., Kar-Narayan S., Bowen C.R. (2019): Modified energy harvesting figures of merit for stress- and strain-driven piezoelectric systems. The European Physical Journal Special Topics, 228, 1537-1554. doi: 10.1140/epjst/e2019-800143-7
12. Hofmann D.P. (2015). Solid State Physics: An Introduction. $2^{\text {nd }}$ ed. Wiley-VCH

13. Gibiansky L.V., Torquato S. (1997): On the use of homogenization theory to design optimal piezocomposites for hydrophone applications. Journal of the Mechanics and Physics of Solids, 45, 689-708. doi: 10.1016/S0022-5096(96)00106-8

14. Nelli Silva E.C., Ono Fonseca J. S., Kikuchi N. (1997): Optimal design of piezoelectric microstructures. Computational Mechanics, 19, 397-410. doi: 10.1007/s004660050188

15. Pabst W. (2020): Effective properties of porous piezoelectric ceramics (in preparation).

16. Piazza D., Galassi C., Barzegar A., Damjanovic D. (2008): Dielectric and piezoelectric properties of PZT ceramics with anisotropic porosity. Journal of Electroceramics, 24, 170-176. doi: 10.1007/s10832-008-9553-8

17. Lee J.-K. (2005): An analytical study on prediction of effective properties in porous and non-porous piezoelectric composites. Journal of Mechanical Science and Technology, 19, 2025-2031. doi: 10.1007/BF02916495

18. Hoshina T., Takizawa K., Li J., Kasama T., Kakemoto H., Tsurumi T. (2008): Domain size effect on dielectric properties of barium titanate ceramics. Japanese Journal of Applied Physics, 47, 7607-7611. doi: 10.1143/jjap.47.7607

19. Maiwa H. (2008): Preparation and properties of $\mathrm{BaTiO}_{3}$ ceramics by spark plasma sintering. Japanese Journal of Applied Physics, 47, 7646-7649. doi: 10.1143/jjap.47.7646

20. TakeuchiT., Tabuchi M., Kageyama H.(1999): Preparation of dense $\mathrm{BaTiO}_{3}$ ceramics with submicrometer grains by spark plasma sintering. Journal of American Ceramic Society, 82, 939-943. doi: 10.1111/j.1151-2916.1999.tb01857.x

21. Yang W.G., Zhang B.P., Ma N., Zhao L. (2012): High piezoelectric properties of $\mathrm{BaTiO}_{3}-x \mathrm{LiF}$ ceramics sintered at low temperatures. Journal of the European Ceramic Society, 32, 899-904. doi: 10.1016/j.jeurceramsoc.2011.10.054

22. Kar-Gupta R., Venkatesh T. (2006): Electromechanical response of porous piezoelectric materials. Acta Materialia, 54, 4063-4078. doi: 10.1016/j.actamat.2006.04.037

23. Iyer S., Venkatesh T.A. (2011): Electromechanical response of (3-0) porous piezoelectric materials: effects of porosity shape. Journal of Applied Physics, 110, 034109-1-034109-8. doi: 10.1063/1.3622509

24. Dunn M.L., Taya M. (1993): Electromechanical properties of porous piezoelectric ceramics. Journal of American Ceramic Society, 76, 697-706. doi: 10.1111/j.1151-2916.1993. tb06637.x

25. Kuscer D., Kocjan A., Majcen M., Meden A., Radan K., Kovač J., Malič B. (2019): Evolution of phase composition and microstructure of sodium potassium niobate - based ceramic during pressure-less spark plasma sintering and post-annealing. Ceramics International, 45, 10429-10437. doi: 10.1016/j.ceramint.2019.02.102

26. Shen Z.Y., Li, J.F. (2010): Enhancement of piezoelectric constant $d_{33}$ in $\mathrm{BaTiO}_{3}$ ceramics due to nano-domain structure. Journal of the Ceramic Society of Japan, 118, 940-943. doi: $10.2109 /$ jcersj2.118.940

27. Joshi J. H., Kanchan D. K., Joshi M. J., Jethva H. O., Parikh K. D. (2017): Dielectric relaxation, complex impedance and modulus spectroscopic studies of mix phase rod like cobalt sulfide nanoparticles. Materials Research Bulletin, 93, 63-73. doi: 10.1016/j.materresbull.2017.04.013

28. Priya S., Nahm S. (2012). Lead-Free Piezoelectrics. Springer. 